\title{
Projection of Temperature-Related Excess Mortality by Integrating Population Adaptability Under Changing Climate - China, 2050s and 2080s
}

\author{
Zhiying Sun ${ }^{1,2, x}$; Qing Wang ${ }^{1,2 \times}$; Chen Chen'; Yang Yang'; Meilin Yan ${ }^{4}$;

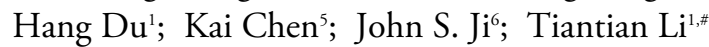

\section{Summary \\ What is already known about this topic? \\ An increasing number of studies have projected temperature-related mortality, but few consider the change of population's adaptability to future temperature and mortality burden from cold and heat effects. \\ What is added by this report? \\ This study offers a comprehensive characterization of human adaptability and excess mortality burden of temperature across various regions of China. \\ What are the implications for public health practice? \\ The temperature-related excess mortality was projected to increase in the 2050s and decrease in the 2080s. Heat adaptability was projected to increase in the future, but along with the rising temperatures, the heat- related excess mortality continuously rose, except for the low-speed rising scenario. Although the excess mortality of cold was projected to decrease in the nearer future, it might not keep declining in the long run, due to the decreasing cold-adaptability, which deserves more attention.}

Rising temperatures due to changing climate is a major public health concern. There is a great need to better estimate the disease burden related to temperature in China, considering changing population adaptation. A two-stage analysis was used in this study to obtain effect-modifiers in temperaturemortality relationships in 105 counties of China, then 3 united scenarios were constructed, future curves were fitted, and the numbers of attributable deaths in the 2050s and 2080s were estimated. Compared with the baseline period, the future cold effects show an upward trend, and the heat effects downward, indicating adaptability to cold would reduce while to heat would increase. The future temperature-related excess mortality was projected to increase in the 2050s and decrease in the 2080s, and cold-related mortality had a similar trend; however, heat-related mortality generally showed a continuously rising trend. Developed areas had greater cold effects and faced an increase of heat effects, while developing regions faced different situations, indicating different mitigation measures were needed. The medium-speed scenario could be the most appropriate developing scenario for China in the future, providing important sustainable policy implications.

Increasing temperatures under a changing climate are one of the major public health concerns in the 21st century. According to the Fifth Report of the Intergovernmental Panel on Climate Change (2013), the future global temperature will increase by $0.3{ }^{\circ} \mathrm{C}-4.8{ }^{\circ} \mathrm{C}$ under the different representative concentration paths (RCPs) by 2100. In 2070-2099, the annual averaged temperature was projected to increase by $1.9{ }^{\circ} \mathrm{C}-3.3{ }^{\circ} \mathrm{C}$ in China (1). China may face a larger burden of disease from a warming climate in the near future (2).

Studies have shown that human adaptability and adaptation measures can greatly affect the health effects of temperature (3). The adaptability to heat has been well-studied and will probably increase according to these previous studies, but the adaptability to cold remains unclear, although it is critical in projecting the temperature-related mortality burden (3-4). Additionally, in recent years, many studies have established a matrix of shared socioeconomic pathways-representative concentration paths (SSPRCPs) to represent future human adaptability to temperature (5). However, there is a certain relationship between SSPs and RCPs, and each RCP in some aspects is corresponding with certain socioeconomic development pathways, and it may be unreasonable to simply use the matrix (G).

To address these gaps, this report constructed three united scenarios by linking the social economic development and climate change scenarios and 
projected the future mortality burden caused by high and low temperature in China under each scenario.

This paper included 105 counties distributed over the 7 geographical regions of the mainland of China (Supplementary Figure S1 and Supplementary Table S1, available in http://weekly.chinacdc.cn/) and defined the baseline period as 2013-2017 and two future periods as 2050s (2041-2070) and 2080s (2071-2099) based on the literature. This report conducted the project through three main steps (Supplementary Figure S2, available in http://weekly. chinacdc.cn/). First, the report modeled the exposureresponse relationship between temperature and mortality in 105 counties through distributed lag nonlinear model (DLNM) and a meta-regression. Through the Wald test, Cochran Q test, and $\mathrm{I}^{2}$ in the regression, the report determined the effect modifiers, including the population size, birth rate, mortality, gross domestic product (GDP), air conditioning possession rate, heating in winter, latitude, and provinces (Supplementary Tables S2-S3, available in http://weekly.chinacdc.cn/). Second, predicting the temperature-morality relationship curves in the 2050s and 2080s. Three united scenarios (low, medium, and high-speed scenarios) were established by integrating the effect-modifiers and based on the mapping relationship between SSPs and the RCPs for future temperature, birth rate, mortality, and gross GDP (Supplementary Tables S4-S6, Supplementary Material, available in http://weekly.chinacdc.cn/). All these analyses were carried out using the packages "dlnm" and "mvmeta" in R (version 3.3.2, R Foundation for Statistical Computing, Vienna, Austria).

Figure 1 and Supplementary Table S7 (available in http://weekly.chinacdc.cn/) respectively showed the curves and the quantitative results between temperature and mortality at the median of the 5 general circulation models (GCM) under different united scenarios. The future cold effects were projected to increase with time, but the heat effects would decrease with time. Among the three scenarios, the future cold effects and heat effects both would be the greatest under the high-speed scenario.

The excess mortality from temperature under all three scenarios was projected to generally increase in the 2050s and decrease in the 2080s compared with the baseline period (Figure 2 and Supplementary Figure S3, available in http://weekly.chinacdc.cn/). Cold-related mortality would increase in the 2050s and decrease in the 2080s under the low-speed scenario and decrease in both the 2050s and the 2080s under the medium- and high-speed scenarios. Heat-related mortality had different trends: decreasing in the lowspeed scenario, and increasing in the medium- and the high-speed scenarios. Using the mid-level IPSL model and the medium-speed scenario as an example, the excess mortality from cold-and-net effects of temperature were projected to have minor changes (decrease by $5.7 \%$ and increase by $5.3 \%$, respectively) in the 2050 s and decrease by $81.7 \%$ and $46.6 \%$ in the 2080s, compared with the baseline period. The excess mortality from heat was projected to increase by $62.7 \%$ and $138.0 \%$ in the 2050 s and 2080 s, respectively. Taken together, the medium speed scenario was estimated to have the least temperature-related excess mortality (Supplementary Table S8, available in
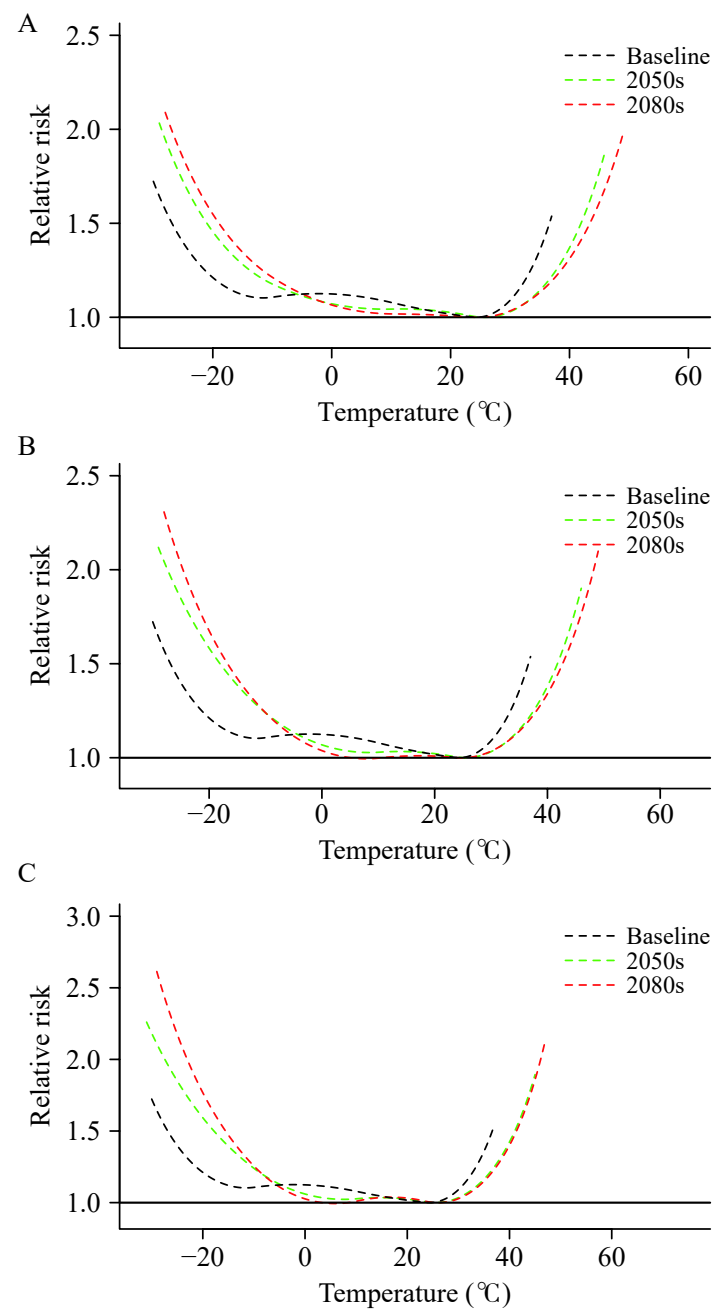

FIGURE 1. Future relationships between temperature and mortality in three periods (baseline, 2050s, and 2080s) in China under 3 united scenarios. (A) The low-speed scenario; (B) The medium-speed scenario; (C) The highspeed scenario. 
http://weekly.chinacdc.cn/). The number of coldrelated mortality was generally larger than the heatrelated excess mortality, except for the numbers in the 2080s under the medium and high-speed scenarios.

The temperature-related excess mortality would increase in the 2050s and decline in the 2080s (the East, the North, and the Central) or keep decreasing (Northeast, Northwest, and Southwest), and all the regions have the temperature-related excess mortality decreasing at last, except for South China, where it shows a rising trend (Figure 3, Supplementary Figure S4, and Supplementary Table S9, available in http://weekly.chinacdc.cn/).

\section{DISCUSSION}

This report offers a comprehensive characterization of human adaptability and excess mortality burden of temperature across various regions of China in three future united scenarios, which fully considered the mapping relationships between the demographic characteristics of China and the SSPs, which provide more realistic estimates than previous studies.

The finding of an increase in heat adaptability is consistent with numerous previous studies (7-9), which may be caused by changes or differences in human physiological mechanism adjustment (3), socioeconomic development, the usage rate of air conditioning, and early warning systems (10-11). However, our study also indicated a declining trend in cold adaptability, which has not been reported before. Along with global warming, heat adaptability is increasing, and at the same time, cold adaptability may decrease due to reduced exposure to cold environments (๑).

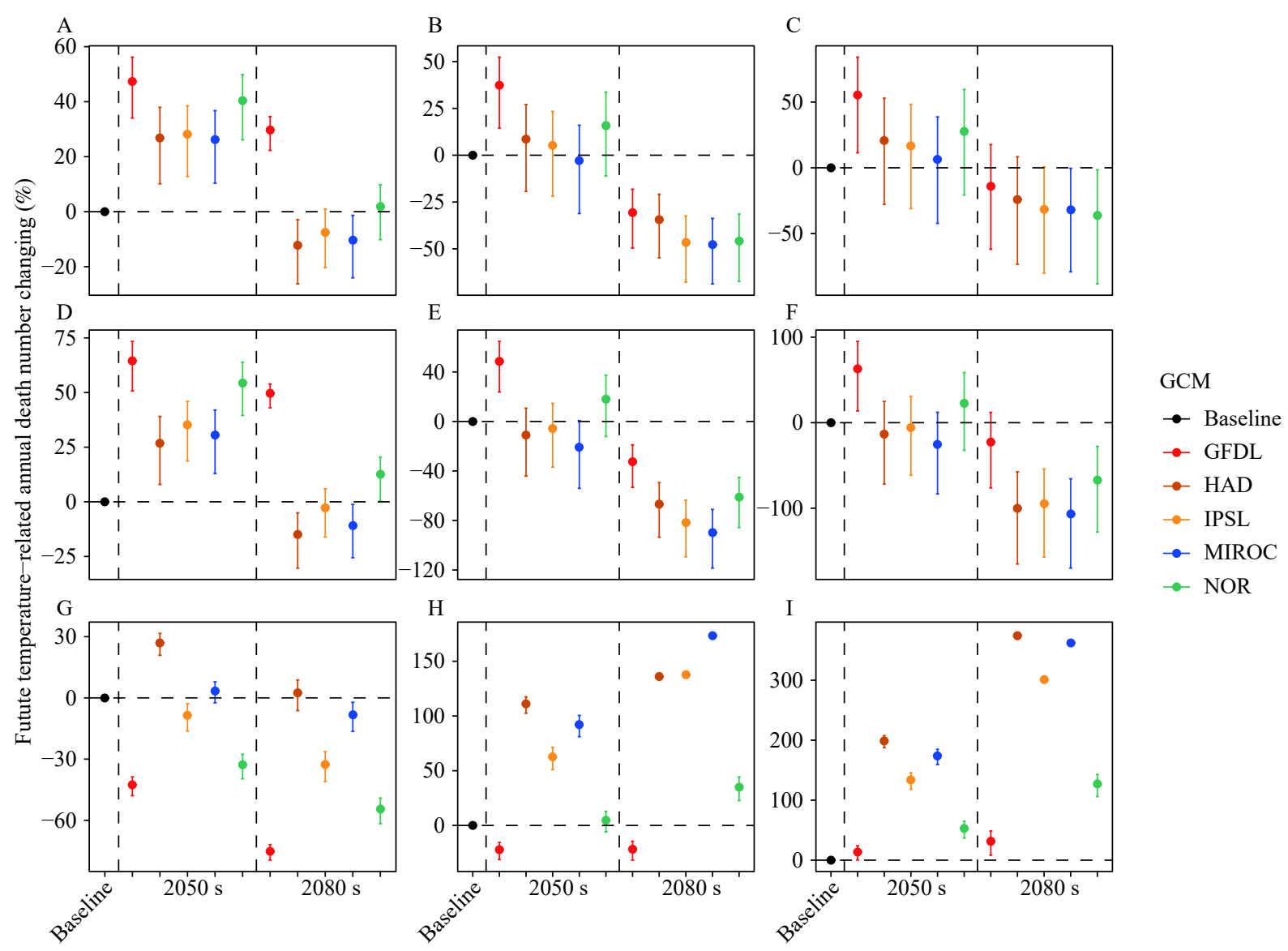

FIGURE 2. Changes (\%) in projected annual death number caused by temperature in 3 periods (baseline, 2050s, and 2080s) in China under three united scenarios. (A) Net effect under low-speed scenario; (B) Net effect under medium-speed scenario; (C) Net effect under high-speed scenario; (D) Cold effect under low-speed scenario in China; (E) Cold effect under medium-speed scenario; (F) Cold effect under high-speed scenario in China; (G) Heat-effect under low-speed scenario; (H) Heat-effect under medium-speed scenario; (I) Heat-effect under high-speed scenario.

Abbreviations: GCM=general circulation model; GFDL=GFDL-ESM2M; HAD=HadGEM2-ES; MIROC=MIROC-ESM-CHEM; NOR=NorESM1-M; IPSL=IPSL-CM5A-LR. 

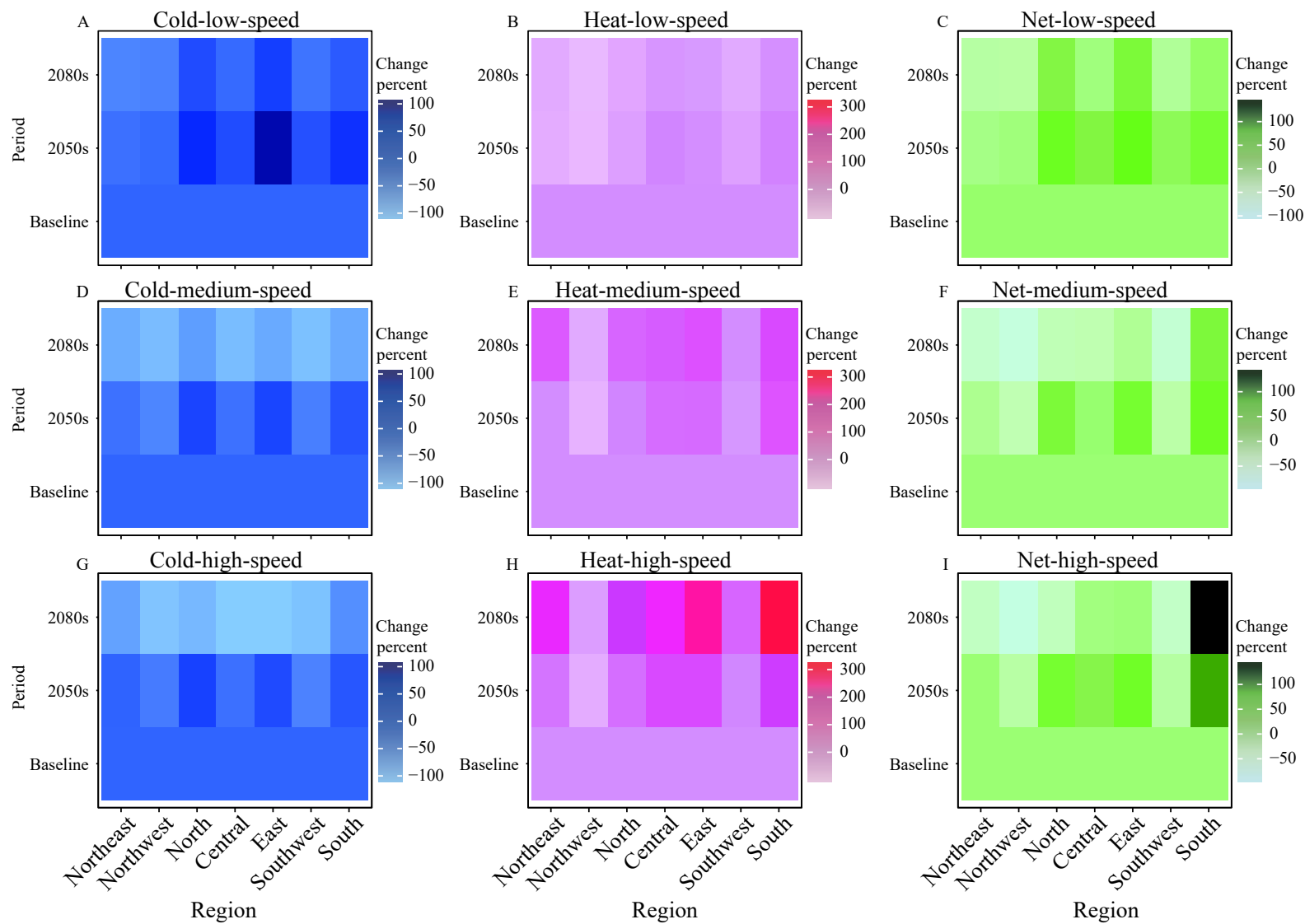

FIGURE 3. Changes (\%) in temperature-related annual death number in seven regions of China in 3 periods (baseline, 2050s, and 2080s) under 3 united scenarios. (A) The cold-related mortality burden under the low-speed scenario; (B) The heat-related mortality burden under the low-speed scenario; (C) The temperature-related mortality burden under the lowspeed scenario; (D) The cold-related mortality burden under the medium-speed scenario; (E) The heat-related mortality burden under the medium-speed scenario; $(F)$ The temperature-related mortality burden under the medium-speed scenario; (G) The cold-related mortality burden under the high-speed scenario; $(\mathrm{H})$ The heat-related mortality burden under the highspeed scenario; (I) The temperature-related mortality burden under the high-speed scenario.

The report also found a generally increasing trend of heat-related excess mortality, and the cold-related and the total excess mortality were generally increasing in the 2050s and followed by a more obvious decrease in the 2080s. The trend is inconsistent with previous studies in the US, Europe, and the Republic of Korea $(5,12)$. The inconsistency may be due to the differences in the sets of adaptation scenarios. Gosling et al. found that the adaptive modeling is a key part of future temperature-related mortality risk projection studies (3-4). Compared with previous studies, this report introduced more socioeconomic variables as adaptation indicators that may modify the temperature-mortality relationship, and the report fully considered the mapping relationship between birth rate, mortality, and SSP, and constructed three united scenarios instead of a simple matrix of the SSPs and RCPs.

There were differences in the changing trends of the temperature-related excess mortality in different geographical regions of China under different united scenarios, which may be caused by both temperature and socioeconomic differences. First, the northwestern, southwestern, and northeastern regions have relatively lower temperatures, but the temperature will rise along with global warming, more attention should be paid to the disease burden caused by high temperatures in the future. Second, Central China, South China, North China, and East China generally had higher development levels, better medical resources, and better resilience to health risks from temperature changes. In these regions, it is worth paying attention to both the high and low temperatures in the 2050s, and more attention should be paid to the impact of heat in the 2080s. South China should prioritize responding to the health risk associated with temperatures, as it is the only region in China that has the temperature-related mortality increasing in all three 
scenarios.

This study was subject to some limitations. First, the estimation relied heavily on future projection data, which brought some uncertainties. Second, this projection did not consider the change of population age structure, so the future mortality burden due to high and low temperature might be underestimated as China is experiencing a stage of population aging and the elderly are more vulnerable to non-optimal temperatures. Future studies should pay attention to these aspects and provide more insights for policymaking.

In summary, the findings of this report suggest that the temperature-related excess mortality was projected to increase in the 2050s and decrease in the 2080s. Heat adaptability was projected to increase in the future, but along with rising temperatures, the heatrelated excess mortality showed a continuously rising trend, except for low-speed scenarios; although the mortality burden due to the cold was projected to decrease in the nearer future, it might not keep declining in the long run due to the decreasing coldadaptability, which deserves more attention. Different regions would need different adaptation policies according to the patterns of temperature-related health risk and considering the differences in geographic, climate, demographic, and economic characteristics.

Funding: The Special Foundation of Basic Science and Technology Resources Survey of Ministry of Science and Technology of China (Grant No. 2017FY101204) and National High-level Talents Special Support Plan of China for Young Talents..

doi: $10.46234 / \mathrm{ccdcw} 2021.174$

\# Corresponding author: Tiantian Li, litiantian@nieh.chinacdc.cn.

\footnotetext{
China CDC Key Laboratory of Environment and Population Health, National Institute of Environmental Health, Chinese Center for Disease Control and Prevention, Beijing, China; ${ }^{2}$ Institute of Environment and Health, Tianjin Center for Disease Control and Prevention, Tianjin, China; ${ }^{3}$ Institute of Urban Meteorology, China Meteorological Administration, Beijing, China; ${ }^{4}$ School of Ecology and Environment, Beijing Technology and Business University, Beijing, China; ${ }^{5}$ Department of Environmental Health Sciences, Yale School of Public Health, New Haven, CT, USA; ${ }^{6}$ Environmental
}

Research Center, Duke Kunshan University, Durham, NC, USA.

${ }^{\&}$ Joint first authors.

Submitted: April 14, 2021; Accepted: August 12, 2021

\section{REFERENCES}

1. Wang L, Chen W. A CMIP5 multimodel projection of future temperature, precipitation, and climatological drought in China. Int J Climatol 2014;34(6):2059 - 78. http://dx.doi.org/10.1002/joc.3822.

2. Climate Change Center of China Meteorological Administration. China blue book on climate change (2019). Beijing: Climate Change Center of China Meteorological Administration; 2019. http://www. cma.gov.cn/root7/auto13139/201905/t20190524_525556.html. (In Chinese).

3. Gosling SN, Hondula DM, Bunker A, Ibarreta D, Liu JG, Zhang XX, et al. Adaptation to climate change: a comparative analysis of modeling methods for heat-related mortality. Environ Health Perspect 2017;125(8):087008. http://dx.doi.org/10.1289/EHP634.

4. Kinney PL, O'Neill MS, Bell ML, Schwartz J. Approaches for estimating effects of climate change on heat-related deaths: challenges and opportunities. Environ Sci Policy 2008;11(1):87 - 96. http://dx. doi.org/10.1016/j.envsci.2007.08.001.

5. Sanderson M, Arbuthnott K, Kovats S, Hajat S, Falloon P. The use of climate information to estimate future mortality from high ambient temperature: a systematic literature review. PLoS One 2017; 12(7):e0180369. http://dx.doi.org/10.1371/journal.pone.0180369.

6. Zhang J, Cao LG, Li XC, Zhan MJ, Jiang T. Advances in shared socioeconomic pathways in IPCC AR5. Progr Inquisit Mutat Climatis 2013;9(3):225 - 8. http://dx.doi.org/10.3969/j.issn.1673-1719.2013. 03.012. (In Chinese).

7. Li YX, Li GX, Zeng Q, Liang FC, Pan XC. Projecting temperaturerelated years of life lost under different climate change scenarios in one temperate megacity, China. Environ Pollut 2018;233:1068-75. http://dx.doi.org/10.1016/j.envpol.2017.10.008.

8. Bobb JF, Peng RD, Bell ML, Dominici F. Heat-related mortality and adaptation to heat in the United States. Environ Health Perspect 2014;122(8):811 - 6. http://dx.doi.org/10.1289/ehp.1307392.

9. Jenkins K, Hall J, Glenis V, Kilsby C, McCarthy M, Goodess C, et al. Probabilistic spatial risk assessment of heat impacts and adaptations for London. Climatic Change 2014;124(1):105 - 17. http://dx.doi.org/10. 1007/s10584-014-1105-4.

10. Hajat S, Vardoulakis S, Heaviside C, Eggen B. Climate change effects on human health: projections of temperature-related mortality for the UK during the 2020s, 2050s and 2080s. J Epidemiol Community Health 2014;68(7):641 - 8. http://dx.doi.org/10.1136/jech-2013202449.

11. Li TT, Horton RM, Kinney PL. Projections of seasonal patterns in temperature- related deaths for Manhattan, New York. Nat Climate Change 2013;3:717 - 21. http://dx.doi.org/10.1038/nclimate1902.

12. Huang CR, Barnett AG, Wang XM, Vaneckova P, FitzGerald G, Tong SL. Projecting future heat-related mortality under climate change scenarios: a systematic review. Environ Health Perspect 2011;119 (12):1681 - 90. http://dx.doi.org/10.1289/ehp.1103456. 


\section{SUPPLEMENTARY MATERIAL}

\section{Data Sources}

The daily temperature data are from the China Meteorological Data Network (http://data.cma.cn/), including the daily average temperature, maximum temperature, and minimum temperature of the counties in 2013-2017. We obtained the daily death number of non-accidental total mortality (International Classification of Diseases 10: A00R99). The socioeconomic data are from the Sixth Population Census in 2010, including total population, birth rate, natural growth rate, mortality, male population, female population, total population under 5 years old, total population above 65 years old, proportion of minority population, and nonagricultural population. The 2010 Gross Domestic Product (GDP) data of each county were calculated by the $1 \mathrm{~km}$ raster data provided by the Resource and Environmental Science Data Center of the Chinese Academy of Sciences (http://www.resdc.cn/). The normalized difference vegetation index data were downloaded from the Geospatial Data Cloud (http://www.gscloud.cn/), and we obtained the maximum monthly vegetation coverage index of each county in 2010. The county-level air conditioning possession rate data are collected from the database of the National Survey on Air Pollution and Population Health carried out by the National Institute of Environmental Health, China CDC. The latitude, province, and heating in winter of each county were obtained directly from the domestic websites.om the domestic websites.

The future daily temperature projections were obtained from five global-scale general circulation models (GCMs) implemented in the fifth phase of the Climate Model Intercomparison Project, including GFDL-ESM2M, HadGEM2-ES, IPSL-CM5A-LR, MIROC-ESM-CHEM, and NorESM1-M under two representative concentration pathways (RCP4.5 and RCP8.5). The temperature projections from five GCMs were further biascorrected to ensure long-term statistical agreement with observations by the Inter-Sectoral Impact Model Intercomparison Project. Using a bilinear interpolation method, the bias-corrected projection of daily temperature on a horizontal resolution of $0.5^{\circ} \mathrm{C} \times 0.5^{\circ} \mathrm{C}$ was downscaled to finer resolution $\left(0.05^{\circ} \mathrm{C} \times 0.05^{\circ} \mathrm{C}\right)$ and then averaged over each county to obtain the daily temperature projection at the county level.

The future demographic data came from the IPCC's SSPs: SSP1 (sustainable development), SSP2 (moderate development), SSP3 (local or inconsistent development), SSP4 (unbalanced development), and SSP5 (conventional development).

The future birth rate and mortality data were from the United Nations (UN) Population Data Centre (website: https://population.un.org/wpp/Download/Standard/Mortality/), including the birth rate and mortality for nine models. The data are at the national level. We obtained the baseline year county-level birth rate and mortality rate from the sixth population census in 2010, and we obtained both rates for 2040 to 2100 based on the UN population datasets.

\section{Methods}

We included 105 counties distributed over the 7 geographical regions of the mainland of China and with varying climate conditions (Supplementary Figure S1 and Supplementary Table S1) and defined the baseline period as 2013-2017 and two future periods as 2050s (2041-2070) and 2080s (2071-2099) based on the literature. Based on the modifier list collected from the literature and on data availability, we collected baseline data and future scenario data, and then conducted the project through three main steps (Supplementary Figure S2).

Exploring effect modifiers between temperature and mortality. We determined the effect-modifiers between temperature and mortality from a two-stage time series analysis in 105 counties. In the first stage, we modeled the nonlinear and delayed exposure-lag response relationship between temperature and mortality with a distributed lag nonlinear model (DLNM), applying a cross-basis spline function with 14 days of lag. In the second stage, we performed a meta-regression based on the baseline exposure-response relationship between temperature and mortality. All the available socioeconomic factors and population data in the 105 counties were substituted into the model as a covariate for the univariate curve meta-regression and used as potential effect-modifiers. The Cochran Q test showed the significance of the meta-regression results (Supplementary Table S2). The $\mathrm{I}^{2}$ showed the heterogeneity of the meta-regression model. We determined the effect modifiers considering by Wald test, Cochran 


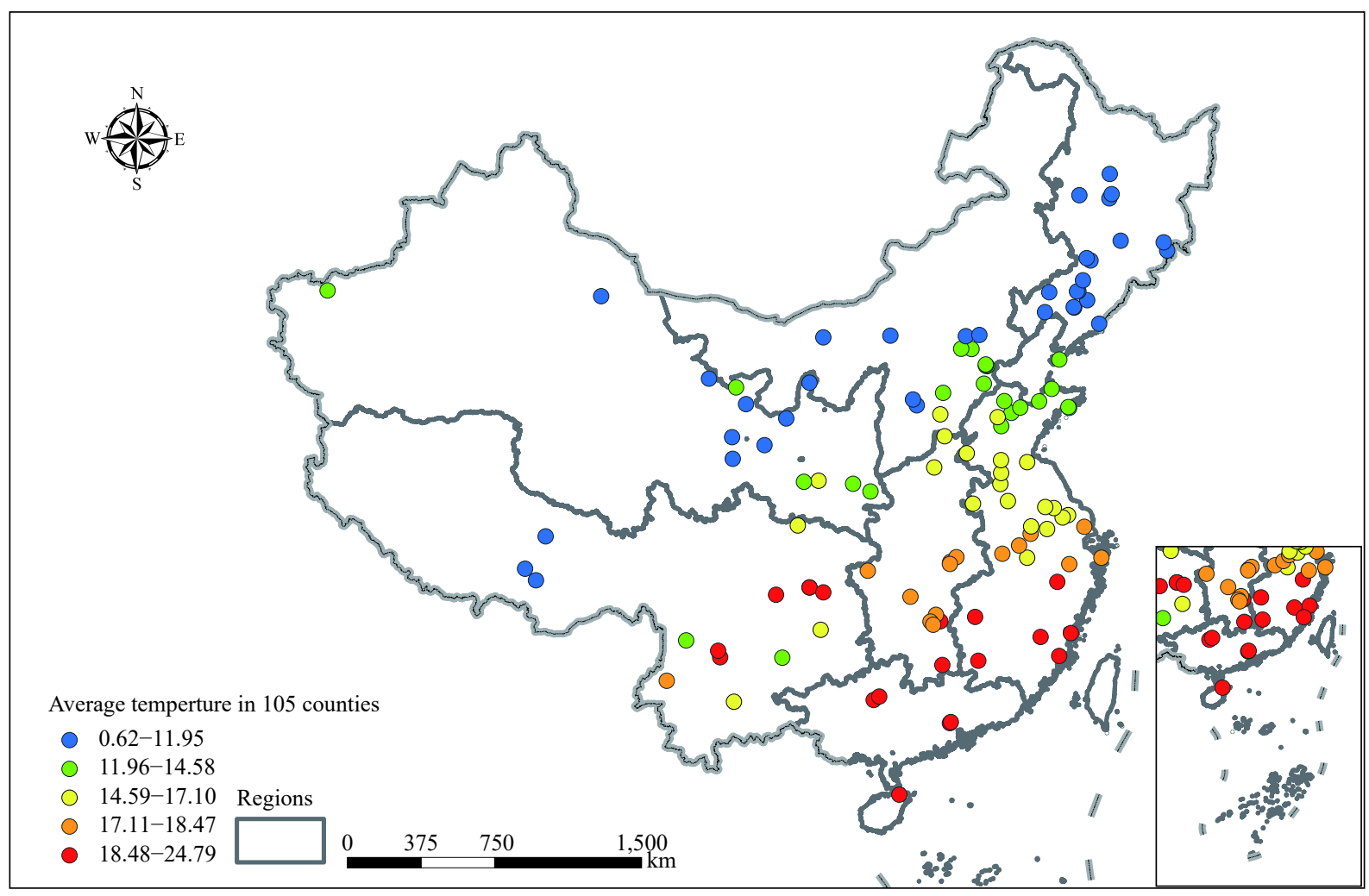

SUPPLEMENTARY FIGURE S1. Distribution of the annual average temperature of 2013-2017 in 105 counties of China $\left({ }^{\circ} \mathrm{C}\right)$.

SUPPLEMENTARY TABLE S1. Describe of meteorological and death data in 105 counties of China, 2013-2017.

\begin{tabular}{|c|c|c|c|c|c|c|c|c|}
\hline Item & Number of days & Mean & SD & Minimum & P25 & P50 & P75 & Maximum \\
\hline \multicolumn{9}{|l|}{ Daily death data } \\
\hline Total & 1,826 & 9.54 & 6.83 & 0 & 5.00 & 8.00 & 13.00 & 221.00 \\
\hline Male & 1,826 & 5.43 & 4.10 & 0 & 2.00 & 5.00 & 8.00 & 121.00 \\
\hline Female & 1,826 & 4.11 & 3.41 & 0 & 2.00 & 3.00 & 6.00 & 100.00 \\
\hline $0-64$ years & 1,826 & 2.38 & 2.08 & 0 & 1.00 & 2.00 & 3.00 & 47.00 \\
\hline $65-74$ years & 1,826 & 1.94 & 1.86 & 0 & 1.00 & 2.00 & 3.00 & 53.00 \\
\hline$\geq 75$ & 1,826 & 5.22 & 4.40 & 0 & 2.00 & 4.00 & 7.00 & 121.00 \\
\hline \multicolumn{9}{|l|}{ Daily Meteorological data } \\
\hline Mean temperature $\left({ }^{\circ} \mathrm{C}\right)$ & 1,826 & 14.26 & 10.94 & -29.5 & 6.70 & 15.90 & 23.10 & 36.50 \\
\hline Maximum temperature $\left({ }^{\circ} \mathrm{C}\right)$ & 1,826 & 19.50 & 10.97 & -24.3 & 11.70 & 21.30 & 28.20 & 42.60 \\
\hline Minimum temperature $\left({ }^{\circ} \mathrm{C}\right)$ & 1,826 & 9.89 & 11.36 & -34.6 & 2.10 & 11.40 & 19.00 & 32.40 \\
\hline Mean relative humidity $(\%)$ & 1,826 & 64.84 & 18.93 & 4.00 & 52.00 & 67.00 & 79.00 & 100.00 \\
\hline
\end{tabular}

Q test, and $\mathrm{I}^{2}$ in the regression (Supplementary Table S3). All these analyses were carried out using the packages "dlnm" and "mvmeta" in R.

Prediction of the temperature-morality relationship in the 2050 s and 2080s. To predict the risk of temperaturerelated mortality in the future, we established the united scenarios by integrating the effect-modifiers determined by the above steps. The effect modifiers we selected are shown in Supplementary Table S3, including the population size, birth rate, mortality, GDP, air conditioning possession rate, heating in winter, latitude, and provinces. The heating in winter, latitude and province data remain constant in the projection. The SSPs are scenarios considering 


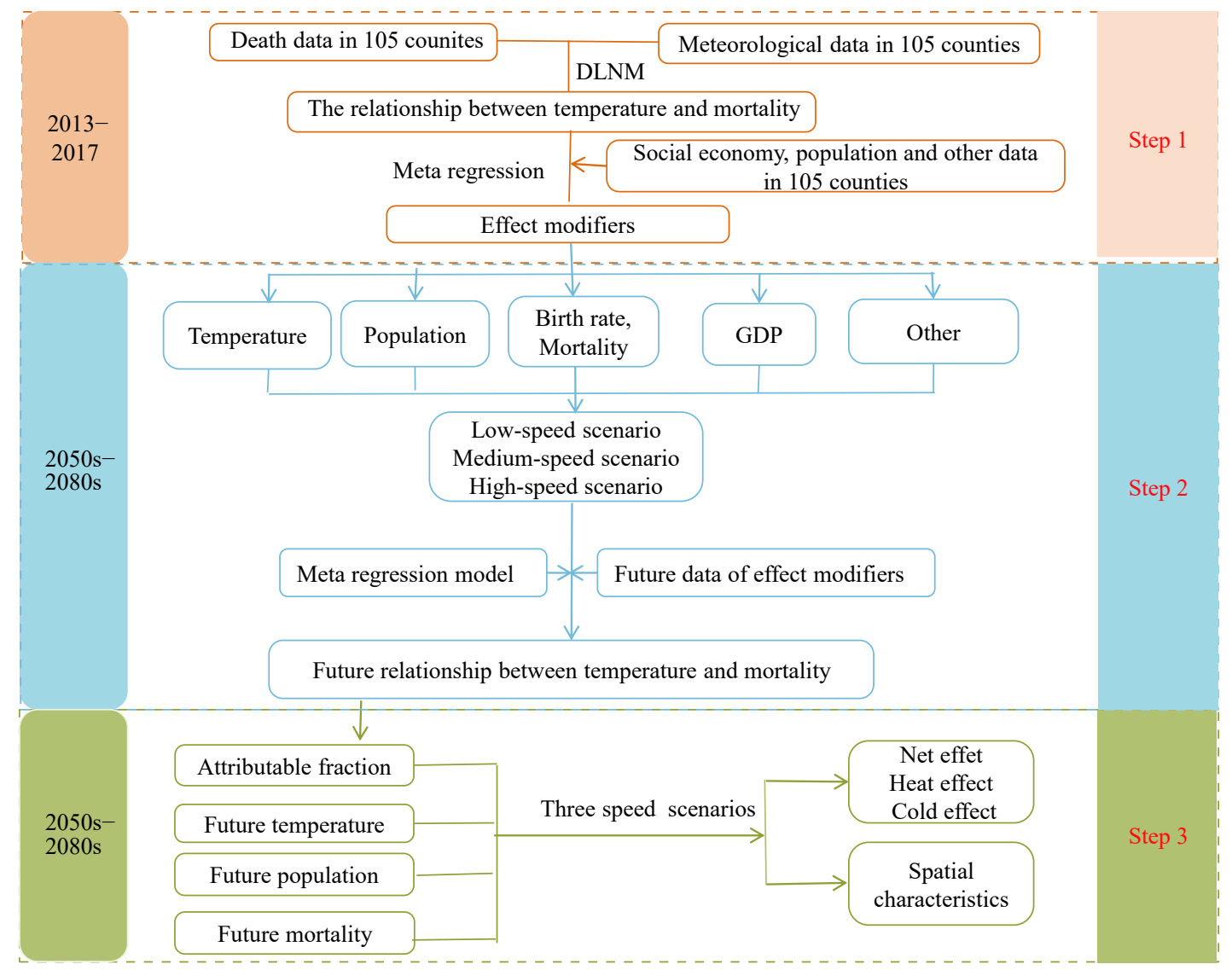

SUPPLEMENTARY FIGURE S2. Flow diagram of the Projection of Temperature-Related Excess Mortality by Integrating Population Adaptability under Changing Climate - China, 2050s-2080s.

Abbreviations: DLNM=distributed lag nonlinear model; GDP=gross domestic product.

many aspects, including economic development, population, environment, and others. We found that the future demographic data from SSPs can be correlated with temperature, population, birth rate, mortality, and GDP from RCPs (Supplementary Tables S4-S5). Therefore, we established a mapping relationship based on the SSPs and future temperature prediction from RCPs, birth rate, and mortality, which were obtained by referring to the future population development report from the United Nations. The future GDP data were taken from the GDP prediction data of China under each SSP in Jiang et al. 2017(1). Thus, we established future united scenarios based on the mapping relationship between SSPs and the RCPs for future temperature, birth rate, mortality, and GDP (Supplementary Tables S4-S5). Three united scenarios were established (Supplementary Table S6) and the future curve of temperature and mortality was estimated under each united scenario using three steps: 1) the future effect modifiers were input into the multivariate meta-regression model, which was established in the previous step, and the coefficient and variance of each county were obtained; 2) the coefficient and variance of the 105 counties were merged at the national level with the "mvmeta" package in R; and 3) based on the coefficient and variance at the national level after the merging stage, the curves of temperature and mortality were fitted in the different periods.

Projection of temperature-related mortality in the 2050s and 2080s. The future annual temperature-related mortality in 105 counties in the 2050s and 2080s was predicted under the three united scenarios. The number of heat-related excess mortalities was projected for days with daily temperatures higher than the MMT, and the number of cold-related excess mortalities was projected for days with daily temperatures lower than the minimum mortality temperature(MMT). The excess mortality from the net effect of temperature was defined as the sum of heat-related excess mortality and cold-related excess mortality. We estimated the attribute fraction $(A F)$ by Formula A; the number of daily excess mortalities attributable to temperature (or cold or heat, the same below) ( $\triangle$ Mortality) were calculated by Formula B, and we calculated the average number of annual temperature-related mortalities in each county. In the formulas, the $i$ represents the county; $R R_{i}$ is the relative mortality risk of this temperature at 

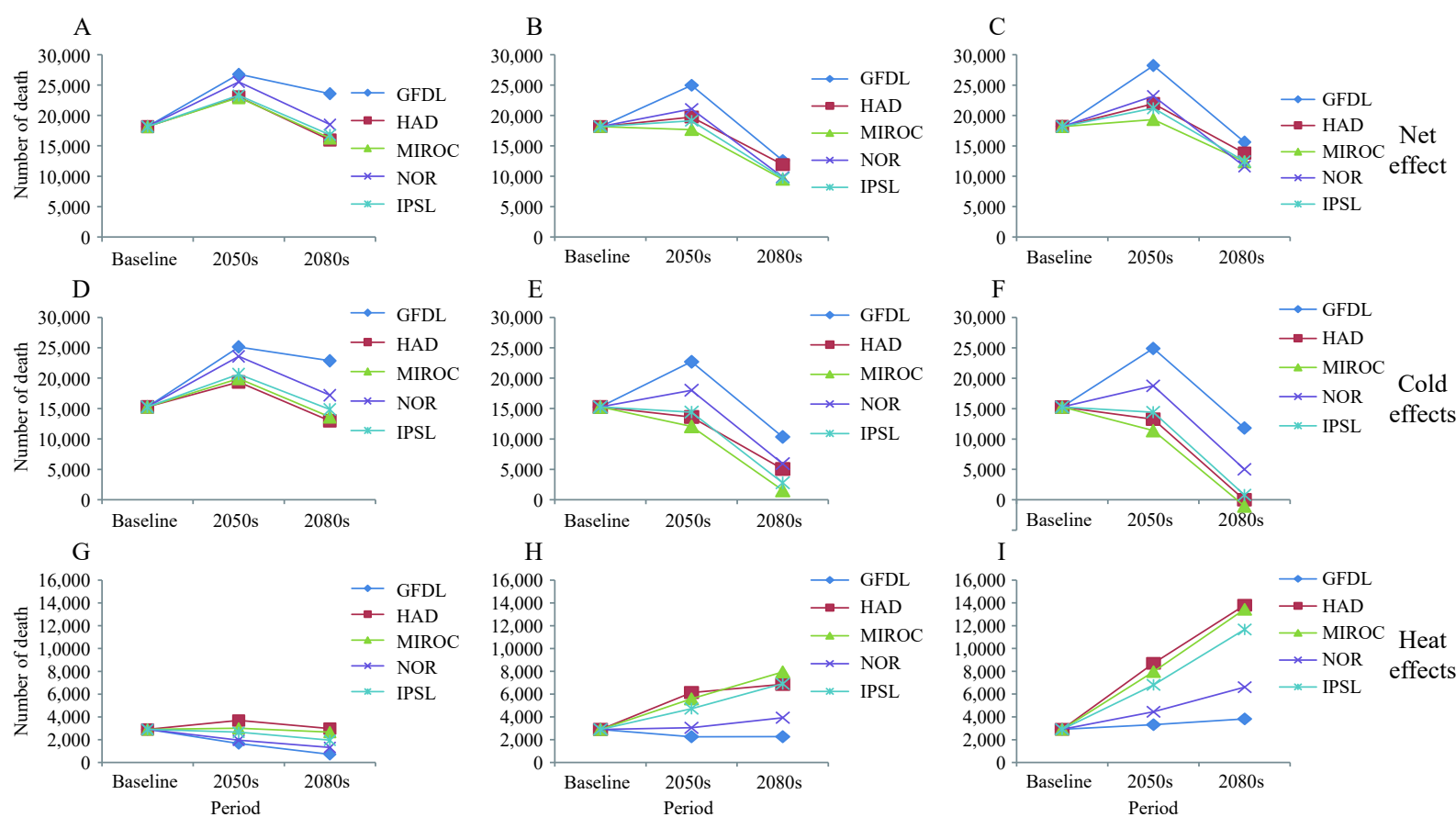

SUPPLEMENTARY FIGURE S3. Change trends of temperature-related annual deaths of different GCMs in 3 periods (baseline, 2050s, and 2080s) in China under 3 united scenarios. (A) Net effect under the low-speed scenario; (B) Net effect under the medium-speed scenario; (C) Net effect under the high-speed scenario; (D) Cold effect under the low-speed scenario; (E) Cold effect under the medium-speed scenario; (F) Cold effect under the high-speed scenario; (G) Heat effect under the low-speed scenario; $(\mathrm{H})$ Heat effect under the medium-speed scenario; (I) Heat effect under the high-speed scenario.

Abbreviations: GCMs=general circulation models; GFDL=GFDL-ESM2M; HAD=HadGEM2-ES; MIROC=MIROC-ESMCHEM; NOR=NorESM1-M; IPSL=IPSL-CM5A-LR.

county $i$ compared with MMT, which is obtained from the future exposure-response relationship curve; $P O P_{i}$ is the future population of county $i ; Y_{O i}$ is the future mortality rate of county $i$; and $\triangle$ Mortality is the number of deaths due to temperature in county $i$. The effect indicator is the number of temperature-related annual mortality due to climate change compared with the number in the baseline period.

$$
\begin{gathered}
A F_{i}=\left(R R_{i}-1\right) / R R_{i} \times 100 \\
\triangle \text { Mortality }=P O P_{i} \times Y_{0 i} \times A F_{i}
\end{gathered}
$$

We also divided the 105 counties into seven groups according to the seven major sub-regions of China (North China, East China, South China, Central China, Northeast China, Northwest China, and Southwest China) and projected their future excess mortality related to cold, heat, and net effects of temperature. 

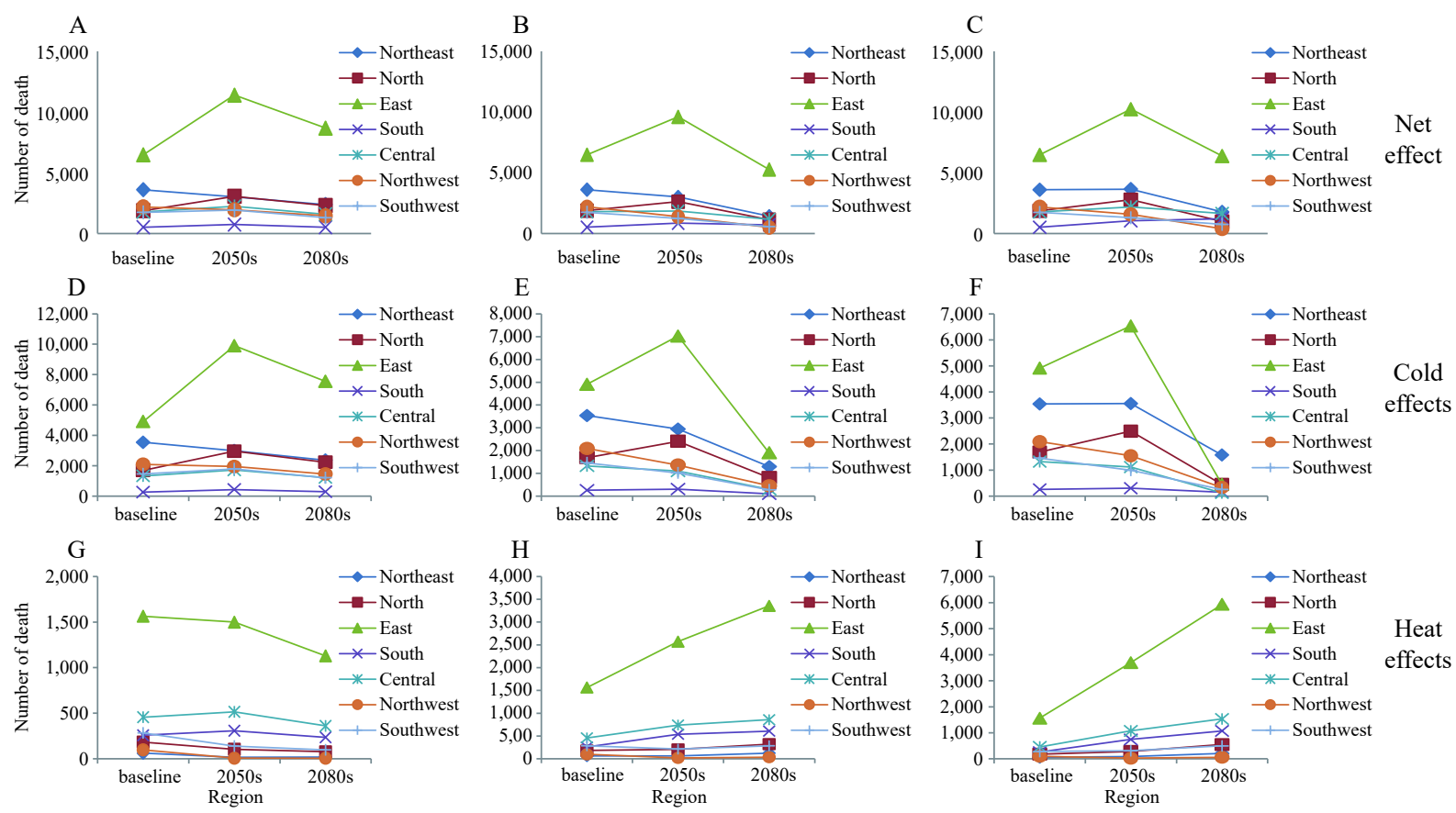

SUPPLEMENTARY FIGURE S4. Change trends of temperature-related annual deaths in 7 regions in 3 periods (baseline,2050s, and 2080s) in China under 3 united scenarios. (A) Net effect under the low-speed scenario; (B) Net effect under the medium-speed scenario; (C) Net effect under the high-speed scenario; (D) Cold effect under the low-speed scenario; (E) Cold effect under the medium-speed scenario; (F) Cold effect under the high-speed scenario; (G) Heat effect under the low-speed scenario; $(\mathrm{H})$ Heat effect under the medium-speed scenario; (I) Heat effect under the high-speed scenario.

SUPPLEMENTARY TABLE S2. Sensitivity analysis of the relationship between temperature and mortality of 105 counties in China, 2013-2017.

\begin{tabular}{llc}
\hline \multicolumn{1}{c}{ Sensitivity analysis } & $\mathbf{I}^{2}$ & $\mathbf{Q}(\boldsymbol{P})$ \\
\hline Core model & $46.8 \%$ & $977.43(P<0.05)$ \\
Add $\mathrm{PM}_{2.5}$ & $46.8 \%$ & $993.10(P<0.05)$ \\
Change degree of time & & $1,016.36(P<0.05)$ \\
$\quad$ Time/df=6 & $48.8 \%$ & $1,087.91(P<0.05)$ \\
Time/df=5 & $52.2 \%$ & \\
Add relative humidity & & $979.69(P<0.05)$ \\
$\quad+\mathrm{ns}(\mathrm{rh} / \mathrm{df}=3)$ & $46.9 \%$ & $977.82(P<0.05)$ \\
$+\mathrm{ns}(\mathrm{rh} / \mathrm{df}=5)$ & $46.8 \%$ & \\
\hline
\end{tabular}


SUPPLEMENTARY TABLE S3. The result of meta-regression including different factors.

\begin{tabular}{cll}
\hline Factors & \multicolumn{1}{c}{$\mathbf{I}^{2}$} & $\mathbf{Q}(\boldsymbol{P})$ \\
\hline The total population & $39.70 \%$ & $838.33(P<0.05)$ \\
Birth rate & $39.40 \%$ & $842.14(P<0.05)$ \\
Mortality & $38.10 \%$ & $823.47(P<0.05)$ \\
GDP & $38.20 \%$ & $825.33(P<0.05)$ \\
Air-conditioning ownership & $38.70 \%$ & $832.03(P<0.05)$ \\
Heating & $37.40 \%$ & $813.23(P<0.05)$ \\
Latitude & $35.40 \%$ & $789.22(P<0.05)$ \\
Province & $36.00 \%$ & $796.27(P<0.05)$ \\
\hline
\end{tabular}

Note: "l"=meta-regression without adding any factors.

Abbreviations: GDP=gross domestic product

SUPPLEMENTARY TABLE S4. Correlation between Shared Socio-economic Pathways (SSP) and representative concentration paths (RCP).

\begin{tabular}{ccc}
\hline SSP & RCP \\
\hline SSP1 & 4.5 \\
SSP2 & 6.0 \\
SSP3 & 8.5 \\
SSP4 & 8.5 \\
SSP5 & $/$ \\
\hline
\end{tabular}

Source: Zhang J, Cao LG, Li XC, Zhan MJ, Jiang T. Advances in shared socio-economic pathways in IPCC AR5. Advances in Climate Change Research, IPCC AR5. Advances in Climate Change Research 2013;9(3):225-8. http://www.climatechange.cn/EN/Y2013/V9//3/225.

SUPPLEMENTARY TABLE S5. Future Shared Socio-economic Pathways (SSP)-involved variables.

\begin{tabular}{cccc}
\hline SSP & Birth rate & Mortality & Education level \\
\hline SSP1 & Low & Low & Rapid development \\
SSP2 & Medium & Medium & Global convergence \\
SSP3 & High & High & Constant enrollment rate \\
SSP4 & Medium & Medium & Constant enrollment rate \\
SSP5 & Low & Low & Rapid development \\
\hline
\end{tabular}

Source: Zhang J, Cao LG, Li XC, Zhan MJ, Jiang T. Advances in shared socio-economic pathways in IPCC AR5. Advances in Climate Change Research 2013;9(3):225-8. http://www.climatechange.cn/EN/Y2013/V9/I3/225.

SUPPLEMENTARY TABLE S6. Future united scenario settings*.

\begin{tabular}{llll}
\hline \multicolumn{1}{l}{ United Scenarios } & \multicolumn{1}{c}{ Low-speed scenario } & Medium-speed scenario & High-speed scenario \\
\hline Temperature & RCP8.5, 5GCMs & RCP8.5, 5GCMs & RCP4.5, 5GCMs \\
Population & SSP3 & SSP4 & SSP1 \\
Birth rate & High & Medium & Low \\
Mortality & High & Medium & Low \\
GDP & 2050s and 2080s increase by 410\% & 2050s and 2080s increase by 570\% & 2050s and 2080s increase by 660\% \\
Air conditioning & and 420\%, respectively & and 500\%, respectively & and 680\%, respectively \\
possession rate & 100\%, respectively & and 150\%, respectively & and 200\%, respectively \\
\hline * The three colors represent low, medium, and high levels from light to dark, respectively. &
\end{tabular}


SUPPLEMENTARY TABLE S7. The heat and cold effects in different scenarios and periods in China.

\begin{tabular}{|c|c|c|c|c|}
\hline Periods & Scenarios & $\begin{array}{c}\text { Heat effects-RR }(95 \% \mathrm{Cl}) 32{ }^{\circ} \mathrm{C} \\
(99 \%) \text { vs. MMT }(\%)\end{array}$ & $\begin{array}{c}\text { Cold effect-RR }(95 \% \mathrm{Cl})-15^{\circ} \mathrm{C} \\
(1 \%) \text { vs. MMT }(\%)\end{array}$ & MMT $\left({ }^{\circ} \mathrm{C}\right)$ \\
\hline \multirow[t]{2}{*}{ Baseline period } & I & $17.09(14.99,9.23)$ & $12.04(9.81,14.31)$ & 23.8 \\
\hline & Low-speed & $6.36(5.33,7.41)$ & $28.16(23.65,32.85)$ & 25.6 \\
\hline \multirow[t]{3}{*}{ 2050s } & Medium-speed & $6.77(5.61,7.95)$ & $38.58(32.14,45.34)$ & 25.4 \\
\hline & High-speed & $7.36(6.13,8.60)$ & $39.39(32.15,47.04)$ & 25.5 \\
\hline & Low-speed & $6.47(5.25,7.69)$ & $34.60(29.55,39.87)$ & 24.6 \\
\hline \multirow[t]{2}{*}{$2080 s$} & Medium-speed & $6.77(5.67,7.89)$ & $42.13(35.28,49.32)$ & 25.5 \\
\hline & High-speed & $6.35(5.15,7.57)$ & $47.17(38.17,56.75)$ & 25.4 \\
\hline
\end{tabular}

Note: "/"=No scenarios in the baseline period.

Abbreviation: $\mathrm{Cl}=$ confidence interval; $\mathrm{MMT}=$ the minimum mortality temperature.

SUPPLEMENTARY TABLE S8. Future temperature-related annual death number with 5 GCMs in 3 periods (baseline, 2050s, and 2080s) in China under 3 united scenarios (the low, medium, and high-speed scenarios).

\begin{tabular}{|c|c|c|c|c|c|c|c|}
\hline \multirow[b]{2}{*}{ GCM } & \multirow[b]{2}{*}{$\begin{array}{l}\text { Baseline period } \\
(95 \% \mathrm{Cl})\end{array}$} & \multicolumn{3}{|c|}{$2050 s$} & \multicolumn{3}{|c|}{$2080 s$} \\
\hline & & $\begin{array}{l}\text { Low-speed } \\
(95 \% \mathrm{Cl})\end{array}$ & $\begin{array}{l}\text { Medium-speed } \\
(95 \% \mathrm{Cl})\end{array}$ & $\begin{array}{c}\text { High-speed } \\
(95 \% \mathrm{Cl})\end{array}$ & $\begin{array}{l}\text { Low-speed } \\
(95 \% \mathrm{Cl})\end{array}$ & $\begin{array}{l}\text { Medium-speed } \\
(95 \% \mathrm{Cl})\end{array}$ & $\begin{array}{l}\text { High-speed } \\
(95 \% \mathrm{Cl})\end{array}$ \\
\hline \multicolumn{8}{|c|}{ Temperature-related annual death } \\
\hline GFDL & $\begin{array}{c}18,178 \\
(14,716-21,592)\end{array}$ & $\begin{array}{c}26,791 \\
(19,725-33,726)\end{array}$ & $\begin{array}{c}24,961 \\
(16,850-32,905)\end{array}$ & $\begin{array}{c}28,219 \\
(16,391-39,765)\end{array}$ & $\begin{array}{c}23,580 \\
(17,993-29,060)\end{array}$ & $\begin{array}{r}12 \\
(7,414\end{array}$ & $\begin{array}{c}15,629 \\
(5,597-25,404)\end{array}$ \\
\hline HAD & $\begin{array}{c}18,178 \\
(14,716-21,592)\end{array}$ & $\begin{array}{c}23,057 \\
(16,205-29,786)\end{array}$ & $\begin{array}{c}19,740 \\
(11,876-27,451)\end{array}$ & $\begin{array}{c}21,944 \\
(10,623-33,015)\end{array}$ & $\begin{array}{c}15,953 \\
(10,852-20,967)\end{array}$ & $\begin{array}{c}11,922 \\
(6,650-17,090)\end{array}$ & $\begin{array}{c}13,787 \\
(3,921-23,415)\end{array}$ \\
\hline MIROC & $\begin{array}{c}18,178 \\
(14,716-21,592)\end{array}$ & $\begin{array}{c}22,945 \\
(16,239-29,531)\end{array}$ & $\begin{array}{c}17,663 \\
(10,129-25,054)\end{array}$ & $\begin{array}{c}19,341 \\
(8,488-29,959)\end{array}$ & $\begin{array}{c}16,286 \\
(11,176-21,306)\end{array}$ & $\begin{array}{c}9,499 \\
(4,600-14,309)\end{array}$ & $\begin{array}{c}12,393 \\
(3,069-21,501)\end{array}$ \\
\hline NOR & $\begin{array}{r}18 \\
(14,716\end{array}$ & $\begin{array}{c}25,522 \\
(18,559-32,357)\end{array}$ & $\begin{array}{r}2 \\
(13,08\end{array}$ & $(11,66$ & $\begin{array}{r}1 \varepsilon \\
(13,21\end{array}$ & $\begin{array}{r}9 \\
(4,802\end{array}$ & $\begin{array}{r}11 \\
(1,719\end{array}$ \\
\hline IPSL & $\begin{array}{c}18,178 \\
(14,716-21,592)\end{array}$ & $\begin{array}{c}23,308 \\
(16,596-29,899)\end{array}$ & $\begin{array}{r}19 \\
(11,481\end{array}$ & $\begin{array}{r}21 \\
(10,143\end{array}$ & $\begin{array}{l}08 \\
21,805)\end{array}$ & $\begin{array}{c}9,707 \\
(4,740-14,582)\end{array}$ & $\begin{array}{c}12,456 \\
(2,934-21,752)\end{array}$ \\
\hline \multicolumn{8}{|c|}{ Cold-related annual death } \\
\hline GFDL & $\begin{array}{c}15,271 \\
(12,224-18,275)\end{array}$ & $\begin{array}{c}25,125 \\
(18,428-31,692)\end{array}$ & $\begin{array}{r}22 \\
(15,135 \\
\end{array}$ & $\begin{array}{r}24, \\
(13,892 \\
12\end{array}$ & $\begin{array}{c}22,858 \\
(17,483-28,128)\end{array}$ & $\begin{array}{c}10,321 \\
(5,712-14,833)\end{array}$ & $\begin{array}{c}11,808 \\
(2,897-20,472)\end{array}$ \\
\hline HAD & $\begin{array}{r}15 \\
(12,224\end{array}$ & $\begin{array}{c}19,365 \\
(13,194-25,420)\end{array}$ & $\begin{array}{r}13 \\
(6,831\end{array}$ & $\begin{array}{r}13 \\
(3,459\end{array}$ & $\begin{array}{r}12 \\
(8,516\end{array}$ & $\begin{array}{r}5,06 \\
(784-9\end{array}$ & $\begin{array}{c}3 \\
(-7,989-7,782)\end{array}$ \\
\hline MIROC & $\begin{array}{r}15,271 \\
(12,224-18\end{array}$ & $\begin{array}{c}19,938 \\
(13,808-25,953)\end{array}$ & $\begin{array}{c}12,076 \\
(5,618-18,400)\end{array}$ & $\begin{array}{r}11,37 \\
(2,031-20\end{array}$ & $\begin{array}{c}13,619 \\
(9,095-18,060)\end{array}$ & $\begin{array}{c}1,554 \\
(-2,262-5,293)\end{array}$ & $\begin{array}{c}-1,042 \\
(-8,570-6,293)\end{array}$ \\
\hline NOR & $\begin{array}{c}15,271 \\
(12,224-18,275)\end{array}$ & $\begin{array}{c}23,568 \\
(17,056-29,956)\end{array}$ & $\begin{array}{c}18,009 \\
(10,739-25,123)\end{array}$ & $\begin{array}{r}18, \\
(8,259-\end{array}$ & $\begin{array}{r}17 \\
(12,26\end{array}$ & $\begin{array}{c}5,924 \\
(1,744-10,018)\end{array}$ & $\begin{array}{c}5,012 \\
(-3,417-13,213)\end{array}$ \\
\hline IPSL & $\begin{array}{c}15,271 \\
(12,224-18,275)\end{array}$ & $\begin{array}{c}20,650 \\
(14,510-26,674)\end{array}$ & $\begin{array}{c}14,408 \\
(7,719-20,956)\end{array}$ & $\begin{array}{c}14,413 \\
(4,708-23,885)\end{array}$ & $\begin{array}{c}14,850 \\
(10,251-19,363)\end{array}$ & $\begin{array}{c}2,791 \\
(-1,139-6,641)\end{array}$ & $\begin{array}{c}797 \\
(-6,994-8,383)\end{array}$ \\
\hline \multicolumn{8}{|c|}{ Heat-related annual death } \\
\hline GFDL & $\begin{array}{c}2,906 \\
(2,491-3,397)\end{array}$ & $\begin{array}{c}1,667 \\
(1,297-2,034)\end{array}$ & $\begin{array}{c}2,261 \\
(1,715-2,803)\end{array}$ & $\begin{array}{c}3,310 \\
(2,499-4,115)\end{array}$ & $\begin{array}{c}722 \\
(510-932)\end{array}$ & $\begin{array}{c}2,273 \\
(1,701-2,840)\end{array}$ & $\begin{array}{c}3,821 \\
(2,700-4932)\end{array}$ \\
\hline HAD & $\begin{array}{c}2,906 \\
(2,491-3,397)\end{array}$ & $\begin{array}{c}3,692 \\
(3,011-4,366)\end{array}$ & $\begin{array}{c}6,136 \\
(5,045-7,216)\end{array}$ & $\begin{array}{c}8,693 \\
(7,164-10,205)\end{array}$ & $\begin{array}{c}2,976 \\
(2,336-3,610)\end{array}$ & $\begin{array}{c}6,860 \\
(5,867-7,840)\end{array}$ & $\begin{array}{c}13,784 \\
(11,910-15,634)\end{array}$ \\
\hline MIROC & $\begin{array}{c}2,906 \\
(2,491-3,397)\end{array}$ & $\begin{array}{c}3,007 \\
(2,431-3,578)\end{array}$ & $\begin{array}{c}5,587 \\
(4,510-6,654)\end{array}$ & $\begin{array}{c}7,962 \\
(6,457-9,453)\end{array}$ & $\begin{array}{c}2,667 \\
(2,082-3,247)\end{array}$ & $\begin{array}{c}7,946 \\
(6,863-9,016)\end{array}$ & $\begin{array}{c}13,435 \\
(11,639-15,208)\end{array}$ \\
\hline NOR & $\begin{array}{c}2,906 \\
(2,491-3,397)\end{array}$ & $\begin{array}{c}1,953 \\
(1,503-2,401)\end{array}$ & $\begin{array}{c}3,048 \\
(2,344-3,747)\end{array}$ & $\begin{array}{c}4,444 \\
(3,411-5,469)\end{array}$ & $\begin{array}{c}1,323 \\
(955-1,689)\end{array}$ & $\begin{array}{c}3,927 \\
(3,058-4,787)\end{array}$ & $\begin{array}{c}6,606 \\
(5,135-8,062)\end{array}$ \\
\hline If & $\begin{array}{c}2,906 \\
(2,491-3,397) \\
\end{array}$ & $\begin{array}{c}2,657 \\
(2,086-3,225) \\
\end{array}$ & $\begin{array}{c}4,728 \\
(3,762-5,687) \\
\end{array}$ & $\begin{array}{c}6,798 \\
(5,435-8,149) \\
\end{array}$ & $\begin{array}{c}1,958 \\
(1,470-2,442) \\
\end{array}$ & $\begin{array}{c}6,915 \\
(5,879-7,941) \\
\end{array}$ & $\begin{array}{c}11,658 \\
(9,928-13,369) \\
\end{array}$ \\
\hline
\end{tabular}

Abbreviation: GCM=general circulation model; GFDL=GFDL-ESM2M; HAD=HadGEM2-ES; MIROC=MIROC-ESM-CHEM ; NOR=NorESM1-M; IPSL=IPSL-CM5A-LR. 
SUPPLEMENTARY TABLE S9. Future temperature-related annual deaths in 3 periods (baseline, 2050s and 2080s) in 7 regions of China under 3 united scenarios (the low, medium, and high-speed scenarios).

\begin{tabular}{|c|c|c|c|c|c|c|c|}
\hline \multirow[b]{2}{*}{ Regions } & \multirow{2}{*}{$\begin{array}{l}\text { Baseline period } \\
(95 \% \mathrm{Cl})\end{array}$} & \multicolumn{3}{|c|}{ 2050s } & \multicolumn{3}{|c|}{ 2080s } \\
\hline & & $\begin{array}{c}\text { Low-speed } \\
(95 \% \mathrm{Cl})\end{array}$ & $\begin{array}{c}\text { Medium-speed } \\
(95 \% \mathrm{Cl})\end{array}$ & $\begin{array}{l}\text { High-speed } \\
(95 \% \mathrm{Cl})\end{array}$ & $\begin{array}{l}\text { Low-speed } \\
(95 \% \mathrm{Cl})\end{array}$ & $\begin{array}{c}\text { Medium-speed } \\
(95 \% \mathrm{Cl})\end{array}$ & $\begin{array}{l}\text { High-speed } \\
(95 \% \mathrm{Cl})\end{array}$ \\
\hline \multicolumn{8}{|c|}{ Temperature-related annual death } \\
\hline Northeast & $\begin{array}{c}3,601 \\
(2963-4,229)\end{array}$ & $\begin{array}{c}3,008 \\
(2,348-3,653)\end{array}$ & $\begin{array}{c}3,004 \\
(2,211-3,776)\end{array}$ & $\begin{array}{c}3,647 \\
(2,488-4,770)\end{array}$ & $\begin{array}{c}2,380 \\
(1,880-2,869)\end{array}$ & $\begin{array}{c}1,419 \\
(899-1,925)\end{array}$ & $\begin{array}{c}1,783 \\
(730-2,802)\end{array}$ \\
\hline North & $\begin{array}{c}1,872 \\
(1,528-2,212)\end{array}$ & $\begin{array}{c}3,062 \\
(2,218-3,889)\end{array}$ & $\begin{array}{c}2,613 \\
(1,642-3,562)\end{array}$ & $\begin{array}{c}2,784 \\
(1,403-4,128)\end{array}$ & $\begin{array}{c}2,305 \\
(1,685-2,912)\end{array}$ & $\begin{array}{c}1,132 \\
(488-1,762)\end{array}$ & $\begin{array}{c}997 \\
(-290-2,247)\end{array}$ \\
\hline East & $\begin{array}{c}6,476 \\
(5,252-7684)\end{array}$ & $\begin{array}{c}11,400 \\
(7,982-14,758)\end{array}$ & $\begin{array}{c}9,601 \\
(5,542-13,584)\end{array}$ & $\begin{array}{c}10,230 \\
(4,422-15,915)\end{array}$ & $\begin{array}{c}8,683 \\
(5,996-11,323)\end{array}$ & $\begin{array}{c}5,256 \\
(2,599-7,866)\end{array}$ & $\begin{array}{c}6,378 \\
(1,342-11,304)\end{array}$ \\
\hline South & $\begin{array}{c}516 \\
(398-632)\end{array}$ & $\begin{array}{c}738 \\
(541-933)\end{array}$ & $\begin{array}{c}843 \\
(593-1,090)\end{array}$ & $\begin{array}{c}1,049 \\
(718-1,376)\end{array}$ & $\begin{array}{c}520 \\
(368-670)\end{array}$ & $\begin{array}{c}706 \\
(529-880)\end{array}$ & $\begin{array}{c}1,223 \\
(917-1,525)\end{array}$ \\
\hline Central & $\begin{array}{c}1,783 \\
(1,443-2,118)\end{array}$ & $\begin{array}{c}2,231 \\
(1,600-2,851)\end{array}$ & $\begin{array}{c}1,840 \\
(1,149-2,519)\end{array}$ & $\begin{array}{c}2,191 \\
(1,130-3,230)\end{array}$ & $\begin{array}{c}1,582 \\
(1,110-2,046)\end{array}$ & $\begin{array}{c}1,154 \\
(705-1,596)\end{array}$ & $\begin{array}{c}1,654 \\
(817-2,473)\end{array}$ \\
\hline Northwest & $\begin{array}{c}2,189 \\
(1,771-2,601)\end{array}$ & $\begin{array}{c}1,958 \\
(1,431-2,474)\end{array}$ & $\begin{array}{c}1,381 \\
(867-1,883)\end{array}$ & $\begin{array}{c}1,580 \\
(777-2,361)\end{array}$ & $\begin{array}{c}1,457 \\
(1,071-1,835)\end{array}$ & $\begin{array}{c}489 \\
(182-789)\end{array}$ & $\begin{array}{c}388 \\
(-232-991)\end{array}$ \\
\hline Southwest & $\begin{array}{c}1,741 \\
(1,362-2,116)\end{array}$ & $\begin{array}{c}1,928 \\
(1,346-2,501)\end{array}$ & $\begin{array}{c}1,231 \\
(680-1,772)\end{array}$ & $\begin{array}{c}1,303 \\
(524-2,066)\end{array}$ & $\begin{array}{c}1,300 \\
(880-1,714)\end{array}$ & $\begin{array}{c}559 \\
(239-873)\end{array}$ & $\begin{array}{c}753 \\
(166-1,328)\end{array}$ \\
\hline \multicolumn{8}{|c|}{ Cold-related annual death } \\
\hline Northeast & $\begin{array}{c}3,538 \\
(2,915-4152)\end{array}$ & $\begin{array}{c}2,990 \\
(2,337-3,629)\end{array}$ & $\begin{array}{c}2,942 \\
(2,169-3,694)\end{array}$ & $\begin{array}{c}3,555 \\
(2,426-4,649)\end{array}$ & $\begin{array}{c}2,361 \\
(1,869-2,841)\end{array}$ & $\begin{array}{c}1296 \\
(805-1773)\end{array}$ & $\begin{array}{c}1576 \\
(575-2542)\end{array}$ \\
\hline North & $\begin{array}{c}1,689 \\
(1,375-1,999)\end{array}$ & $\begin{array}{c}2,957 \\
(2,140-3,758)\end{array}$ & $\begin{array}{c}2,406 \\
(1,486-3,304)\end{array}$ & $\begin{array}{c}2,495 \\
(1,186-3,770)\end{array}$ & $\begin{array}{c}2,227 \\
(1,631-2,811)\end{array}$ & $\begin{array}{c}811 \\
(230-1379)\end{array}$ & $\begin{array}{c}444 \\
(-732-1584)\end{array}$ \\
\hline East & $\begin{array}{c}4,912 \\
(3,900-5,910)\end{array}$ & $\begin{array}{c}9,900 \\
(6,796-12,946)\end{array}$ & $\begin{array}{c}7,029 \\
(3,495-10,491)\end{array}$ & $\begin{array}{c}6,533 \\
(1,473-11,478)\end{array}$ & $\begin{array}{c}7,553 \\
(5,141-9,921)\end{array}$ & $\begin{array}{c}1900 \\
(-213-3972)\end{array}$ & $\begin{array}{c}444 \\
(-3637-4424)\end{array}$ \\
\hline South & $\begin{array}{c}257 \\
(181-333)\end{array}$ & $\begin{array}{c}430 \\
(295-563)\end{array}$ & $\begin{array}{c}305 \\
(158-449)\end{array}$ & $\begin{array}{c}301 \\
(112-487)\end{array}$ & $\begin{array}{c}284 \\
(186-380)\end{array}$ & $\begin{array}{c}98 \\
(18,177)\end{array}$ & $\begin{array}{c}151 \\
(12,288)\end{array}$ \\
\hline Central & $\begin{array}{c}1,326 \\
(1,048-1,600)\end{array}$ & $\begin{array}{c}1,715 \\
(1,174-2,246)\end{array}$ & $\begin{array}{c}1,100 \\
(537-1,652)\end{array}$ & $\begin{array}{c}1,114 \\
(241-1,968)\end{array}$ & $\begin{array}{c}1,220 \\
(822-1,611)\end{array}$ & $\begin{array}{c}297 \\
(-30-618)\end{array}$ & $\begin{array}{c}121 \\
(-502-730)\end{array}$ \\
\hline Northwest & $\begin{array}{c}2,091 \\
(1,690-2,487)\end{array}$ & $\begin{array}{c}1,950 \\
(1,425-2,464)\end{array}$ & $\begin{array}{c}1,362 \\
(854-1,859)\end{array}$ & $\begin{array}{c}1,550 \\
(756-2,323)\end{array}$ & $\begin{array}{c}1,451 \\
(1,068-1,827)\end{array}$ & $\begin{array}{c}454 \\
(156-746)\end{array}$ & $\begin{array}{c}329 \\
(-277-916)\end{array}$ \\
\hline Southwest & $\begin{array}{c}1,458 \\
(1,116-1,795)\end{array}$ & $\begin{array}{c}1,788 \\
(1,233-2,334)\end{array}$ & $\begin{array}{c}1,016 \\
(509-1,515)\end{array}$ & $\begin{array}{c}991 \\
(275-1,693)\end{array}$ & $\begin{array}{c}1,203 \\
(805-1,593)\end{array}$ & $\begin{array}{c}275 \\
(2-543)\end{array}$ & $\begin{array}{c}251 \\
(-253-745)\end{array}$ \\
\hline \multicolumn{8}{|c|}{ Heat-related annual death } \\
\hline Northeast & $\begin{array}{c}62 \\
(47-77)\end{array}$ & $\begin{array}{c}18 \\
(11-25)\end{array}$ & $\begin{array}{c}62 \\
(41-82)\end{array}$ & $\begin{array}{c}92 \\
(62-121)\end{array}$ & $\begin{array}{c}20 \\
(11-28)\end{array}$ & $\begin{array}{c}123 \\
(94-152)\end{array}$ & $\begin{array}{c}207 \\
(155-260)\end{array}$ \\
\hline North & $\begin{array}{c}183 \\
(153-213)\end{array}$ & $\begin{array}{c}105 \\
(78-131)\end{array}$ & $\begin{array}{c}207 \\
(156-258)\end{array}$ & $\begin{array}{c}288 \\
(217-359)\end{array}$ & $\begin{array}{c}78 \\
(55-101)\end{array}$ & $\begin{array}{c}321 \\
(258-383)\end{array}$ & $\begin{array}{c}553 \\
(442-664)\end{array}$ \\
\hline East & $\begin{array}{c}1,564 \\
(1,351-1,775)\end{array}$ & $\begin{array}{c}1,500 \\
(1,186-1,812)\end{array}$ & $\begin{array}{c}2,572 \\
(2,047-3,093)\end{array}$ & $\begin{array}{c}3,697 \\
(2,949-4,437)\end{array}$ & $\begin{array}{c}1,129 \\
(855-1,401)\end{array}$ & $\begin{array}{c}3,356 \\
(2,812-3,895)\end{array}$ & $\begin{array}{c}5,934 \\
(4,978-6,879)\end{array}$ \\
\hline South & $\begin{array}{c}259 \\
(218-299)\end{array}$ & $\begin{array}{c}308 \\
(246-370)\end{array}$ & $\begin{array}{c}539 \\
(435-642)\end{array}$ & $\begin{array}{c}748 \\
(606-889)\end{array}$ & $\begin{array}{c}236 \\
(182-290)\end{array}$ & $\begin{array}{c}607 \\
(511-702)\end{array}$ & $\begin{array}{c}1,072 \\
(905-1,237)\end{array}$ \\
\hline Central & $\begin{array}{c}457 \\
(395-518)\end{array}$ & $\begin{array}{c}516 \\
(426-605)\end{array}$ & $\begin{array}{c}740 \\
(612-867)\end{array}$ & $\begin{array}{c}1,077 \\
(889-1,262)\end{array}$ & $\begin{array}{c}362 \\
(289-435)\end{array}$ & $\begin{array}{c}858 \\
(735-978)\end{array}$ & $\begin{array}{c}1,532 \\
(1,319-1,743)\end{array}$ \\
\hline Northwest & $\begin{array}{c}98 \\
(82-115)\end{array}$ & $\begin{array}{c}8 \\
(5-10)\end{array}$ & $\begin{array}{c}19 \\
(13-24)\end{array}$ & $\begin{array}{c}29 \\
(21-38)\end{array}$ & $\begin{array}{c}6 \\
(4-8)\end{array}$ & $\begin{array}{c}35 \\
(27-43)\end{array}$ & $\begin{array}{c}60 \\
(45-75)\end{array}$ \\
\hline Southwest & $\begin{array}{c}284 \\
(246-321)\end{array}$ & $\begin{array}{c}140 \\
(113-167)\end{array}$ & $\begin{array}{c}214 \\
(171-257)\end{array}$ & $\begin{array}{c}311 \\
(249-373)\end{array}$ & $\begin{array}{c}98 \\
(75-120)\end{array}$ & $\begin{array}{c}284 \\
(237-330)\end{array}$ & $\begin{array}{c}501 \\
(419-583)\end{array}$ \\
\hline
\end{tabular}

\section{REFERENCES}

1. Jiang T, Zhao J, Jing C, Cao LG, Wang YJ, Sun HM, et al. National and Provincial Population Projected to 2100 Under the Shared Socioeconomic Pathways in China. Climate Change Research 2017;13(2):128-137. http://www.climatechange.cn/EN/10.12006/j.issn.1673-1719.2016.249. 